Background: Transforming growth factor- $\beta 1$ (TGF- $\beta 1$ ) is a multifunctional cytokine involved in cancer development. The diagnostic significance of serum levels of transforming growth factor- $\beta 1$ (sTGF- $\beta 1$ ) in the oesophageal squamous cell carcinoma (ESCC) remains unclear. The aim of the study was to analyze sTGF- $\beta 1$ concentrations in ESCC patients. The sTGF- $\beta 1$ levels were assessed according to the clinical parameters in cancer patients. We determined STGF- $\beta 1$ concentrations in ESCC patients before and after oesophagectomy. The correlation between STGF- $\beta 1$ and serum levels of vascular endothelial growth factor (sVEGF-A) was examined as well.

Material and methods: The study included 115 patients with ESCC and 57 healthy controls. Concentrations of sTGF- $\beta 1$ were measured by ELISA tests and were compared with clinical parameters of cancer patients. Serum samples for sTGF- $\beta 1$ evaluation 3 months after surgical resection were available in 41 cases.

Results: Serum TGF- $\beta 1$ level was significantly higher in ESCC compared to the control group $(p<0.001)$. Serum levels of TGF- $\beta 1$ positively correlated with the depth of tumour invasion ( $p=0.042$ ). There were no differences in sTGF- $\beta 1$ levels in patients stratified by the presence of regional and distant metastases and stage of cancer progression. The level of sTGF- $\beta 1$ was significantly lower in ESCC patients after oesophagectomy than before surgical treatment $(p=0.002)$. A positive correlation between STGF- $\beta 1$ and SVEGF-A $(p=0.017)$ was observed. Conclusion: TGF- $\beta 1$ seems to play an important role in tumour progression in ESCC. Further studies are needed to evaluate the utility of this cytokine as possible marker of ESCC.

Key words: oesophageal squamous cell carcinoma, transforming growth factor- $\beta 1$, tumourgenesis.

\section{Elevated levels of serum transforming growth factor- $\beta 1$ in oesophageal squamous cell carcinoma patients}

\author{
Dorota Diakowska, Andrzej Lewandowski, Krystyna Markocka-Mączka, \\ Krzysztof Grabowski
}

Department of Gastrointestinal and General Surgery, Silesian Piasts University of Medicine, Wrocław, Poland

\section{Introduction}

Oesophageal squamous cell carcinoma (ESCC) is the most common histological type of oesophageal cancer [1]. The prognosis for patients with ESCC is poor, despite recent substantial improvements in screening, diagnosis and treatment of this tumour. Surgical resection is possible only in $15-20 \%$ of diagnosed patients and 5-years survival is lower than 10\% [2]. The poor outcome observed in ESCC patients is in part related to tumour growth and progression processes, which can be very intensive in this cancer type [3]. For that reason searching for tumour markers allowing for early cancer diagnosis and monitoring of the disease course and treatment effectiveness seem to be very important.

Transforming growth factor- $\beta 1$ (TGF- $\beta 1$ ) is multifunctional regulatory protein that affects on many cellular processes: extracellular matrix formation, apoptosis, immune function, and angiogenesis [3-6]. TGF- $\beta 1$ inhibits the proliferation of normal epithelial cells and early well-differentiated epithelial tumour cells [7]. However, during tumour progression cancer cells lose their sensitivity to inhibitory effects exerted by TGF- $\beta 1$ [5]. In the latest phase of tumour growth the TGF- $\beta 1$ acts as stimulator of angiogenesis and tumour progression and as an inhibitor of host immune functions [8]. A number of studies have demonstrated enhanced tissue expression of TGF- $\beta 1$ in many different malignancies, including breast [9], colorectal [10], small intestine [11], gastric [12] and oesophageal adenocarcinomas [13]. The overexpression of TGF- $\beta 1$ mRNA in ESCC has also been demonstrated [14]. However, a little is known about the concentration of serum TGF- $\beta 1$ (sTGF- $\beta 1$ ) in ESCC patients. The aim of the present study was to analyze STGF- $\beta 1$ concentrations in relation to clinicopathological parameters in ESCC patients. We also examined whether there are any differences between STGF- $\beta 1$ concentrations before and after curative resection of oesophageal tumours.

\section{Material and methods}

The present study included 115 patients ( 23 females and 92 males, median age 61 years) treated for ESCC between 2005 and 2009 in the Department of Gastrointestinal and General Surgery, Silesian Piasts University of Medicine in Wroclaw. Blood samples were collected from ESCC patients preceding any treatment. On the basis of clinical evaluation palliative treatment was administered in 74 patients. In 41 patients surgical exploration resulted in curative oesophagectomy with lymph node dissection. All of these patients were resubmitted to our clinic 3 months following oesophagectomy for the reconstruction procedures and blood was sampled once more for second evaluation. 
According to the TNM classification system for oesophageal carcinoma [15] two tumours were identified as being stage I, 13 tumours as stage II, 26 as stage III, and 74 as stage IV.

Sera from 57 healthy blood donors, obtained from the Regional Centre of Blood Donation and Therapeutics in Wroclaw, Poland were used as a control group. There were 44 males and 13 females, median age 57 years. Blood samples from the peripheral vein were collected in sterile test tubes, clotted (15 min, RT) and centrifuged $(15 \mathrm{~min}, 900 \times \mathrm{g})$. The obtained sera were stored at $-80^{\circ} \mathrm{C}$ until assayed.

Concentrations of STGF- $\beta 1$ were measured by enzymelinked immunosorbent assay (ELISA) using the test supplied by RnDSystems (Abingdon, UK). The sensitivity of the assay was $4.61 \mathrm{pg} / \mathrm{ml}$, the intra-assay coefficient of variation was $1.9-2.9 \%$, and inter-assay coefficient of variation was 6.4-9.3\%. Before running the assay, all samples were activated with $1 \mathrm{M}$ hydrochloric acid, followed by $1.2 \mathrm{M}$ $\mathrm{NaOH} / 0.5 \mathrm{M}$ HEPES. All samples were run in duplicates. For the purpose of correlation analysis, data on SVEGF-A in our patients were retrieved from previous publications [16].

Data distribution was analysed with the Shapiro-Wilk normality test. Concentrations of STGF- $\beta 1$ are presented as median and interquartile range (Q25-Q75). The Mann-Whitney $U$ test applied for groups comparison. The effect of gender and the disease stage was co-examined with Friedman test. The Wilcoxon's matched pairs test was used to analyse differences between the levels of factors before and after surgery. The Spearman's rank correlation test was used for correlation analysis. Values of $p<0.05$ were considered statistically significant. The statistical analyses were performed using Statistica 9.0 software.

The Medical Ethics Committee of Silesian Piasts University of Medicine in Wroclaw, Poland approved the study protocol.

\section{Results}

The concentration of STGF- $\beta 1$ was significantly higher in ESCC patients than in healthy controls, both when oesophagectomy and palliation subgroups were analysed (Table 1). There were no significant differences in concentrations of sTGF- $\beta 1$ between patients with unresectable and resectable tumours.

The associations between sTGF- $\beta 1$ levels and gender, age and cancer TNM status in oesophageal cancer are presented in Table 2. Serum levels of TGF- $\beta 1$ tended to increase with increasing stage of cancer $(p=0.051$ for stage IV vs. stage I + II).
The concentration of sTGF- $\beta 1$ was significantly higher in T4 than in $\mathrm{T} 1+\mathrm{T} 2$ primary tumour extension. No significant differences in STGF- $\beta 1$ concentrations were observed in a reference to patient's age, or regional and distant metastases.

We observed significantly higher sTGF- $\beta 1$ levels in men than in women (Table II). However, the co-examination of gender and the disease stage revealed that gender was not an important factor affecting sTGF- $\beta 1$ levels $(p<0.05)$.

The resection of the tumour resulted in the reduction of sTGF- $\beta 1$ concentration in $74 \%$ (30/41) of patients, markedly decreased ( $>10 \%$ of baseline value) in $61 \%$ (25/41) of patients. Median sTGF- $\beta 1$ decreased from $56.8 \mathrm{ng} / \mathrm{ml}$ (46.9-68.6) before surgery to $45.8 \mathrm{ng} / \mathrm{ml}(37.8-62.0)$ after surgical tumour resection ( $p=0.002$ ) (Fig. 1). However, the concentration of STGF- $\beta 1$ following the oesophagectomy remained higher than in the control group $(p<0.001)$.

We observed a significant overall correlation between sTGF- $\beta 1$ and sVEGF-A, which, however, depended on cancer progression. Statistically significant correlation was observed in patients treated by palliation, but not in patients treated by oesophagectomy (Table 3).

\section{Discussion}

Tumour cells acquire resistance to TGF- $\beta 1$ inhibitory effect and the excess of this cytokine may result in stimulation of angiogenesis, extracellular matrix production and immune suppression [1-5]. Some studies have reported that levels of TGF- $\beta 1$ were significantly elevated in the serum or plasma of patients with liver [17], breast [18], lung [19, 20], and oesophageal cancers $[21,22]$. In the present study we observed significantly higher sTGF- $\beta 1$ levels in ESCC patients as compared to the controls.

Some studies have reported that there was no relationship between STGF- $\beta 1$ levels and disease progression $[14,21]$. However, in our study, serum levels of TGF- $\beta 1$ tended to be higher in advanced oesophageal cancer than those in stage I and II. Similarly, other authors have reported an association between sTGF- $\beta 1$ concentration and cancer progression [7, 23]. An relationship with disease progression has been also reported in oesophageal carcinoma [22, 23]. These results indicate that TGF- $\beta 1$ may play a crucial role in oesophageal cancer development. It can be hypothesized that the circulating TGF- $\beta 1$ in patients with ESCC is elevated, although this did not always result in significant relationship between tumour stage and sTGF- $\beta 1$ levels.

Our studies on association between sTGF- $\beta 1$ levels and clinical variables showed that the STGF- $\beta 1$ concentrations

Table 1. Concentration of serum TGF- $\beta 1$ in total ESCC patients, oesophagectomy and palliation groups and control group

\begin{tabular}{|c|c|c|}
\hline & \multicolumn{2}{|c|}{ sTGF- $\beta 1$ (ng/ml) } \\
\hline & Median (range) & $p$ \\
\hline Controls (C) $(n=57)$ & $28.3(22.5-34.4)$ & ESCC vs. C: $p<0.001^{*}$ \\
\hline $\operatorname{ESCC}(n=115)$ & $55.0(43.4-65.5)$ & E vs. C: $p<0.001^{\star}$ \\
\hline oesophagectomy (E) $(n=41)$ & $56.8(46.9-68.6)$ & P vs. C: $p<0.001^{*}$ \\
\hline palliation $(P) \quad(n=74)$ & $55.0(41.3-63.9)$ & E vs. P: $p=0.865$ \\
\hline
\end{tabular}

Data were compared using Mann-Whitney $U$ test, ${ }^{*}$ statistically significant 
Table 2. Serum TGF- $\beta 1$ concentrations with respect to clinical and pathological characteristics of ESCC

\begin{tabular}{|c|c|c|c|}
\hline & $n$ & Median TGF- $\beta 1$ (ng/ml) & $p$ \\
\hline Age: $\begin{aligned} & \\
& <60 \text { years } \\
& \geq 60 \text { years }\end{aligned}$ & $\begin{array}{l}54 \\
61\end{array}$ & $\begin{array}{l}59.4(41.8-65.5) \\
53.0(39.8-64.0)\end{array}$ & 0.611 \\
\hline $\begin{array}{l}\text { Sex: } \\
\\
\text { women } \\
\text { men }\end{array}$ & $\begin{array}{l}23 \\
92\end{array}$ & $\begin{array}{c}47.9(38.8-64.9) \\
66.2(1399.8-65.3)\end{array}$ & $0.035^{\star}$ \\
\hline $\begin{array}{l}\text { Stage of disease: } \\
\qquad \begin{array}{l}\text { I }+ \text { II } \\
\text { III } \\
\text { IV }\end{array}\end{array}$ & $\begin{array}{l}21 \\
29 \\
65\end{array}$ & $\begin{array}{l}50.7(23.1-67.0) \\
55.3(41.3-63.9) \\
62.5(47.9-67.4)\end{array}$ & $\begin{array}{c}I+\text { II vs. III: } p=0.157 \\
\text { I+ II vs. IV: } p=0.051 \\
\text { III vs. IV: } p=0.205\end{array}$ \\
\hline $\begin{array}{l}\text { Tumour extension }(\mathrm{T}) \text { : } \\
\qquad \begin{array}{c}\text { T2 } \\
\text { T3 } \\
\text { T4 }\end{array}\end{array}$ & $\begin{array}{l}23 \\
49 \\
43\end{array}$ & $\begin{array}{l}53.8(32.5-63.6) \\
59.4(39.8-65.3) \\
64.7(41.3-69.6)\end{array}$ & $\begin{array}{l}\text { T2 vs. T3: } p=0.150 \\
\text { T2 vs. T4: } p=0.042^{*} \\
\text { T3 vs. T4: } p=0.372\end{array}$ \\
\hline $\begin{array}{l}\text { Regional lymph nodes } \\
\text { N0 } \\
\text { N1 }\end{array}$ & $\begin{array}{l}21 \\
94\end{array}$ & $\begin{array}{l}55.0(32.5-68.9) \\
57.8(41.3-63.9)\end{array}$ & 0.693 \\
\hline $\begin{array}{l}\text { Distant metastasis (M): } \\
\text { M0 } \\
\text { M1 }\end{array}$ & $\begin{array}{l}48 \\
67\end{array}$ & $\begin{array}{l}54.6(39.8-63.9) \\
59.7(36.9-67.9)\end{array}$ & 0.327 \\
\hline
\end{tabular}

Data were compared using Mann-Whitney U test, *statistically significant

are significantly higher in $\mathrm{T} 4$ than $\mathrm{T} 1+\mathrm{T} 2$ primary tumours extension. These data are consistent with previous ones $[21,22]$ demonstrating, that plasma TGF- $\beta 1$ level in ESCC patients has been increasing along with the tumour progression. A similar relationship has been found between tissue TGF- $\beta 1$ level and depth of tumour invasion in gastric and lung cancers [7, 12, 24].

Our results suggest that an increase in STGF- $\beta 1$ concentration is associated with tumour progression in patients with ESCC. The reasons for the rise in STGF- $\beta 1$ in oesophageal cancer are not clear. It has been shown that genetic mutation in the TGF- $\beta 1$ signaling pathway could lead to prooncogenic effects during tumourigenesis and the production of TGF- $\beta 1$ by tumour and surrounding stromal elements [25]. This might imply that an elevated sTGF- $\beta 1$ level can be caused by the secretion of TGF- $\beta 1$ into the blood from tumour or surrounding tissues [24, 25].

Our previous studies analyzing the relation between sVEGF-A and clinicopathological findings in gastroesophageal cancer patients have demonstrated that the presence of VEGF-A in ESCC was associated with enhanced tumour extension $[16,26]$. This may indicate that VEGF-A, similar to TGF- $\beta 1$, has a potential to contribute to tumour growth in ESCC. This is in accordance with study of Kitadai et al. [27] where VEGF-A was reported to be associated with increased tumour vascular density. VEGF-A acts as a selective mitogen for endothelial cells and can induce tumour development and progression in oesophageal cancer $[28,29]$.

In this study we demonstrated the relation of STGF- $\beta 1$ with angiogenic SVEGF-A in ESCC, especially in advanced stages of the disease. Our study is in agreement with studies showing the dynamic overexpression of TGF- $\beta 1$ in the latest phase of cancer progression to be connected with the

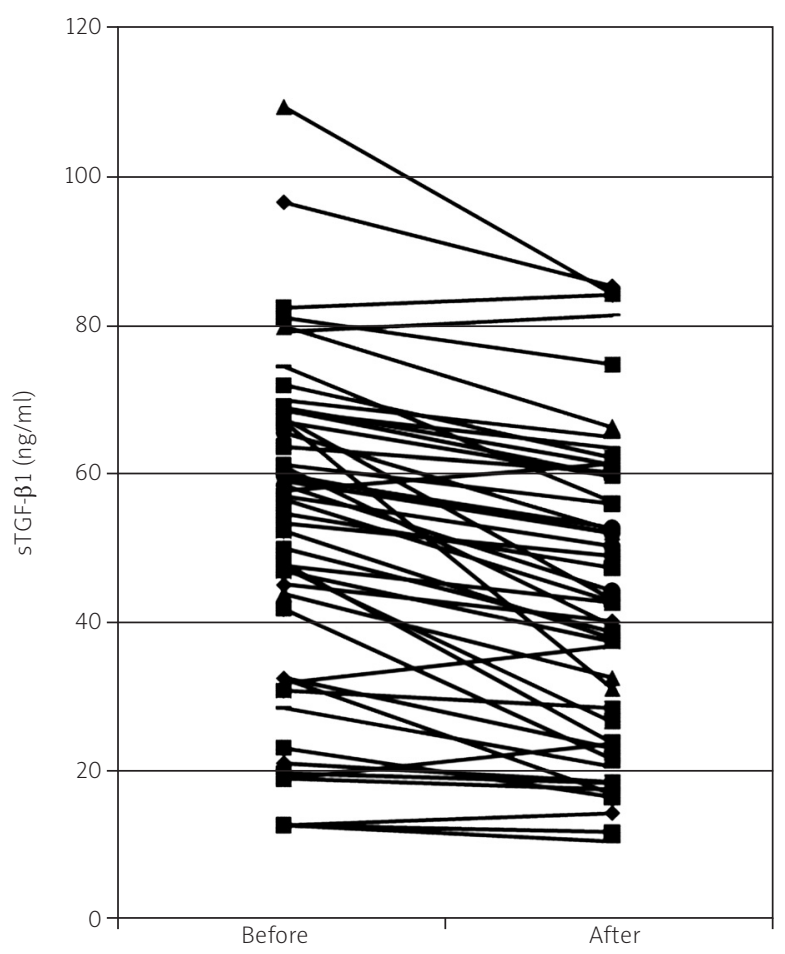

Fig. 1. Serum levels of TGF- $\beta 1$ in patients with ESCC before and after surgical resections of the tumours

Table 3. Correlations between serum levels of TGF- $\beta 1$ and VEGF-A in ESCC patients

$\begin{array}{lll} & \mathrm{R} & p \\ \operatorname{ESCC}(n=115): & 0.29 & 0.017^{*} \\ \text { oesophagectomy }(\mathrm{E})(n=41) & 0.18 & 0.353 \\ \text { palliation }(P)(n=74) & 0.44 & 0.007^{*}\end{array}$

Spearman $R$ test, *statistically significant 
angiogenic processes and the up-regulation of VEGF-A $[28,30]$. Accordingly, Xiong et al. [10] found that the expression of TGF- $\beta 1$ was positively correlated with the expression of VEGF in colorectal cancer. In vitro study of Noma et al. [5] showed, in turn, that TGF- $\beta 1$ could regulate angiogenesis through the release of VEGF from the fibroblasts.

To our knowledge this is the first report analysing differences between concentrations of STGF- $\beta 1$ in patients with ESCC before and after oesophagectomy. Our results showed that STGF- $\beta 1$ level which was elevated preoperatively, significantly decreased after surgical resection of the tumour in a majority of patients. This might imply that primary tumour is an important source of circulating TGF- $\beta 1$. However, sTGF- $\beta 1$ levels remained elevated in almost half of the patients. Moreover, the concentrations in those who experienced STGF- $\beta 1$ reduction following oesophagectomy were higher than found in healthy subjects. These observations suggest that host cells might significantly contribute to sTGF- $\beta 1$ elevation. It is also possible that non-detected lymph node metastases and/or micrometastases can induce secretion of TGF- $\beta 1$ in postoperative patients. The clinical relevance of this finding is that it may hamper the possible application of sTGF- $\beta 1$ determination in patients monitoring for the disease recurrence. Further studies are needed to evaluate the utility of this cytokine as possible marker of ESCC.

Based on our studies, it seems likely that serum TGF- $\beta 1$ levels may be useful as diagnostic tool for the presence of ESCC. It remains possible, that altered serum levels of this cytokine participates in disease progression, rather than acting as a possible marker after surgical resection of tumour. The role of STGF- $\beta 1$ in ESCC growth and prognosis remains to be elucidated. Further studies with larger groups of patients and analysis of TGF- $\beta 1$ levels in other blood fractions (circulating lymphocytes, platelets) are necessary to conclude whether this cytokine have any prognostic value in patients with oesophageal cancer.

\section{Acknowledgements}

We wish to thank Dr Elzbieta Klausa from the Regional Centre of Blood Donation and Therapeutics in Wroclaw, Poland for supply of control sera.

\section{References}

1. Kuwano H, Nakajima M, Miyazaki T, Kato H. Distinctive clinicopathological characteristics in esophageal squamous cell carcinoma. Ann Thorac Cardiovasc Surg 2003; 9: 6-13.

2. Mariette C, Piessen G, Triboulet JP. Therapeutic strategies in oesophageal carcinoma: role of surgery and other modalities. Lancet Oncol 2007; 8: 545-53.

3. Valverde C, Macarulla T, Casado E, Ramos F, Martinelli E, Tabernero J. Novel targets in gastric and esophageal cancer. Critical Rev Oncol Hematol 2006; 59: 128-38.

4. Otrock Z, Mahfouz R, Makarem J, Shamseddine A. Understanding the biology of angiogenesis: Review of the most important molecular mechanisms. Blood Cells Molec Dis 2007; 39: 212-20.

5. Noma K, Smalley K, Lioni M, et al. The essential role of fibroblasts in esophageal squamous cell carcinoma-induced angiogenesis. Gastroenterology 2008; 134: 1981-93.

6. Reiss M. TGF-b and cancer. Microb Infect 1999; 1: 1327-47.

7. Hasegawa Y, Takanashi S, Kanehira Y, Tsushima T, Imai T, Okumura K. Transforming growth factor-b1 level correlates with angiogenesis, tumor progression, and prognosis in patients with nonsmal cell lung carcinoma. Cancer 2001; 91: 964-71.

8. Roberts A, Wakefield L. The two faces of transforming growth factor b in carcinogenesis. PNAS 2003; 100: 8621-23.

9. Boneberg E, Legler D, Hoefer M. Angiogenesis and lymphangiogenesis are downregulated in primary breast cancer. Br J Cancer 2009; 101: 605-14.

10. Xiong B, Gong L, Zhang F, Hu M, Yuan H. TGF-b1 expression and angiogenesis in colorectal cancer tissue. World J Gastroenterol 2002; 8: 496-8.

11. Radhen B, Brucher B, Langner C, Siewert J, Stein H, Sarbia M. Expression of cyclo-oxygenase 1 and 2, prostaglandin E synthase and transforming growth factor b1, and their relationship with vascular endothelial growth factors $A$ and $C$, in primary adenocarcinoma of the small intestine. Br J Surg 2006; 93: 1424-32.

12. Saito H, Tsujitani S, Oka S, et al. The expression of transforming growth factor-b1 is significantly correlated with the expression of vascular endothelial growth factor and poor prognosis of patients with advanced gastric carcinoma. Cancer 1999; 86: 1455-62.

13. Von Rahden BH, Stein HJ, Feith M, et al. Overexpression of TGF-beta1 in esophageal (Barrett's) adenocarcinoma is associated with advanced stage of disease and poor prognosis. Mol Carcinog 2006; 45: 786-94.

14. Gholamin M, Moaven O, Memar B, et al. Overexpression and interactions of interleukin-10, transforming growth factor b1 and vascular endothelial growth factor in esophageal squamous cell carcinoma. Word J Surg 2009; 33: 1439-45.

15. Krzystek-Korpacka M, Matusiewicz M, Diakowska D, et al. Impact of weight loss on circulating IL-1, IL-6, IL-8, TNF-alpha, VEGF-A, VEGF-C and midkine in gastroesophageal cancer patients. Clin Bioch 2007; 40: 1353-60.

16. Sobin LH, Wittekind Ch. TNM classification of malignant tumors. 6th edn. Hoeboken, John Wiley \& Sons, New Jersey 2002.

17. Sacco R, Leuci D, Tortorella C, Fiore G, Marinosci F, Schiraldi O, Antonaci S. Transforming growth factor b1 and soluble Fas serum levels in hepatocellular carcinoma. Cytokine 2000; 12: 811-4.

18. Ivanovic V, Todorovic-Rakovic N, Demajob M. Elevated plasma levels of transforming growth factor-b1 (TGF-b1) in patients with advanced breast cancer: association with disease progression. Eur J Cancer 2003; 39: 454-61.

19. Van de Wiele C, Vyver V, Debruyne C, Philippe J, Van Meerbeeck J. FDG uptake by the bone marrow in NSCLC patients is related to TGF-b1 but not to VEGF or G-CSF serum levels. Eur J Nucl Med Mol Imaging 2008; 35: $519-22$.

20. Duysinx B, Corhay J, Hubin L, Nguyen D, Henket M, Louis R. Diagnostic value of interleukin-6, transforming growth factor-beta1 and vascular endothelial growth factor in malignant pleural effusions. Respir Med 2008; 102: 1708-14.

21. Fukuchi M, Miyazaki T, Fukai Y, et al. Plasma level of transforming growth factor b1 measured from the azygos vein predicts prognosis in patients with esophageal cancer. Clin Cancer Res 2004; 10: 2738-41.

22. Sun S, Jin Y, Yang H, Wei Y, Dong Z. Serum transforming growth factor-b1 level reflects disease status in patients with esophageal carcinoma after radiotherapy. Word I Gastroenterol 2007; 13: 5267-72.

23. Pepper MS. Transforming growth factor-beta vasculogenesis, angiogenesis and vessel wall integrity. Cytokine Growth Factor Rev 1997; 8: 21-43.

24. Lin Y, Kikuchi S, Obata Y, et al. Serum levels of transforming growth factor b1 are significantly correlated with venous invasion in patients with gastric cancer. Gastroenterology 2006; 21: 432-7.

25. Fukai Y, Fukuchi M, Masuda N, et al. Reduced expression of trans forming growth factor-b1 receptors is an unfavorable prognostic factor in human esophageal squamous cell carcinoma. Int J Cancer 2003; 104: $161-6$

26. Krzystek-Korpacka M, Matusiewicz M, Diakowska D, et al. Up-regulation of VEGF-C secreted by cancer cells and not VEGF-A correlates with clinical evaluation of lymph node metastasis in esophageal squamous cell carcinoma (ESCC). Cancer Letters 2007; 249: 171-7.

27. Kitadai Y, Haruma K, Tokutomi T, Tanaka S, Sumii K, Carvalho M, et al. Significance of vessel count and vascular endothelial growth factor in human esophageal carcinomas. Clin Cancer Res 1998; 4: 21952200. 
28. Xie K, Wei D, Shi Q, Huang S. Constitutive and inducible expression and regulation of vascular endothelial growth factor. Cytokine Growth Factor Rev 2004; 15: 297-324.

29. Hirakawa S, Kodama S, Kunstfeld R, Kajiya K, Brown LF, Dietmar M. VEGF-A induces tumor and sentinel lymph node lymphangiogenesis and promotes lymphatic metastasis. J Exp Med 2005; 201: 1089-99.

30. Tammela T, Enholm B, Alitalo K, Paavonen K. The biology of vascular endothelial growth factors. Cardiovasc Res 2005; 65: 550-63.

\section{Address for correspondence}

Dorota Diakowska MD, PhD

Department of Gastrointestinal and General Surgery

Silesian Piasts University of Medicine

M. Sklodowska-Curie 66

50-369 Wroclaw, Poland

fax: +48 717332609

e-mail: ddiakow@chir.am.wroc.pl 